This item was submitted to Loughborough's Research Repository by the author.

Items in Figshare are protected by copyright, with all rights reserved, unless otherwise indicated.

\title{
Do tabloids poison the well of social media? Explaining democratically dysfunctional news sharing
}

PLEASE CITE THE PUBLISHED VERSION

https://doi.org/10.1177/1461444818769689

\section{PUBLISHER}

(C) The authors. Published by SAGE Publications

\section{VERSION}

AM (Accepted Manuscript)

\section{PUBLISHER STATEMENT}

This work is made available according to the conditions of the Creative Commons Attribution-NonCommercialNoDerivatives 4.0 International (CC BY-NC-ND 4.0) licence. Full details of this licence are available at: https://creativecommons.org/licenses/by-nc-nd/4.0/

\section{LICENCE}

CC BY-NC-ND 4.0

\section{REPOSITORY RECORD}

Chadwick, Andrew, Cristian Vaccari, and Ben O'Loughlin. 2018. "Do Tabloids Poison the Well of Social Media? Explaining Democratically Dysfunctional News Sharing". Loughborough University. https://hdl.handle.net/2134/33261. 
Do Tabloids Poison the Well of Social Media? Explaining Democratically-Dysfunctional News Sharing

\title{
Andrew Chadwick
}

Loughborough University, UK

Cristian Vaccari

Loughborough University, UK

\section{Ben O'Loughlin}

Royal Holloway, University of London, UK

\begin{abstract}
The use of social media for sharing political information and the status of news as an essential raw material for good citizenship are both generating increasing public concern. We add to the debates about misinformation, disinformation, and "fake news" using a new theoretical framework and a unique research design integrating survey data and analysis of observed news sharing behaviors on social media. Using a media-as-resources perspective, we theorize that there are elective affinities between tabloid news and misinformation and disinformation behaviors on social media. Integrating four datasets we constructed during the 2017 UK election campaign - individual-level data on news sharing ( $N=1,525,748$ tweets), website data ( $N=17,989$ web domains), news article data ( $N=641$ articles), and data from a custom survey of Twitter users $(N=1,313$ respondents $)$ - we find that sharing tabloid news on social media is a significant predictor of democratically-dysfunctional misinformation and disinformation behaviors. We explain the consequences of this finding for the civic culture of social media and the direction of future scholarship on fake news.
\end{abstract}

\section{Keywords}

news, news sharing, misinformation, disinformation, tabloid news, social media, "fake news"

In New Media \& Society.

Authors' accepted manuscript. Please read the typeset version of this article when it is published at http://journals.sagepub.com/home/nms

\section{Corresponding author:}

Professor Andrew Chadwick, Centre for Research in Communication and Culture, Loughborough University, Loughborough, LE11 3TT, UK.

Email: a.chadwick@lboro.ac.uk 
On Remembrance Sunday, 2016, two UK right-wing tabloid newspapers - the Sun and the Daily Mail — published photos on their websites and social media accounts of Labour Party leader Jeremy Corbyn "dancing a jig" as he made his way to the national remembrance ceremony at the Cenotaph memorial in central London. The Mail's headline was: "Is this really the day to audition for Strictly [Come Dancing], Jeremy? Corbyn appears to dance a jig at the Cenotaph as he waits for the Remembrance Day parade" (Ponsford, 2016). The articles featured six individual photos of Corbyn, shot from some distance away and in quick succession. Positioned side by side on a single canvas, the images gave the impression that the Labour leader was performing a spontaneous "dance." The framing was clear: here was Corbyn, the left-wing pacifist, showing casual disregard for those who lost their lives to war, and, by extension, those across the country participating in their own commemorations. The images were widely shared on social media.

The problem? This news was fabricated. Corbyn had, in fact, been walking alongside one of his constituents, George Durack, a 92-year-old Second World War veteran. The tabloids' picture editors had cropped the photos to exclude Durack. When the full images later emerged online, it was clear that Corbyn's movements were simply the natural gestures of a person walking and talking with a companion.

Links to the photos coursed through social media networks during Remembrance Sunday. Empowered by evidence of Corbyn's supposed misdemeanor, many social media users eagerly circulated the false news among their networks, giving extended life to a factually baseless meme that still exists as we complete this article in early 2018 .

\section{News sharing on social media: identifying uncivic outcomes}

Almost all theoretical perspectives on political communication rest on an ideal of the behaviors and contextual conditions that shape good citizenship. Dewey’s (1927) and 
Habermas's (1996) insistence on the importance of deliberation and learning are obvious cases, but even Lippman's (1922) more skeptical insistence that individuals have irrational and self-serving motives when they communicate with others still relies on an ideal yardstick against which empirical reality is judged and found wanting. The healthy functioning of liberal democracies has long been said to rely upon citizens whose role is to learn about the social and political world, exchange information and opinions with fellow citizens, arrive at considered judgements about public affairs, and put these judgements into action as political behavior. It is equally beyond doubt that, since the onset of modernity, a key circulatory raw material for these acts of citizenship is news (Schudson, 1998).

Yet the status of news as the raw material of good citizenship is currently undergoing something of a crisis. There are now fundamental questions about how the routine use of social media by news producers and citizens is reshaping the civic environments of the advanced democracies. Central to the debate is whether the affordances that enable news to rapidly circulate and recirculate also encourage political expression that is superficial, misleading, or false. What are the necessary ingredients, at both the systemic and individual levels, for falsehood to spread on social media? And when people do share information that misleads or deceives, what are the likely effects on the civic culture of life online?

Emerging research on political misperceptions shows that many citizens hold factually incorrect beliefs about politics. But, as noted in a recent review article (Flynn, Nyhan and Reifler, 2017), little is known about the role of media, let alone social media, in enabling the spread of false information. Our concern in this article is whether the quality of civic culture in social media environments is affected by the routine presence of tabloid news sharing. We consider whether tabloid media are poisoning the well of social media by providing resources for news sharing behavior that is dysfunctional for democracy. Using a unique blend of survey data and digital trace data, we assess whether tabloid news has 
elective affinities with online misinformation, which, following Jack (2017), we define as unintentional behavior that inadvertently misleads, and online disinformation, which we define as intentional behavior that purposively misleads. Overall, our findings shed light on the interdependence between media adaptation and changes in the character of civic life. We argue that democratically-dysfunctional news sharing behavior is a potential systemic outcome of the tabloidization of the UK social media environment.

To understand the interdependence between digital platforms, tabloid news organizations, and social media users, we start from the premise that, more than ever before, news media provide resources for citizens to participate in politically-significant behaviors. As the "active audience" tradition in media research has amply shown, people use news to collectively construct everyday narratives to make sense of public events (for one example see Bird 1998). News sharing on social media is now an essential part of this process. However, we use the term media-as-resources to ground our study in an emergent conceptual mileu, to which we also seek to contribute. We assume that in a complex, multi-faceted media environment characterized by multi-directional information flows (Chadwick, 2017), primary gatekeeping by journalists, and secondary gatekeeping by users (Singer, 2014) research should pay attention to the ways in which individuals enrol specific types of news content as they seek to exercise political agency in the everyday spaces of social media. This perspective builds on Chadwick's (2017) view of media content as resources for intervening in the political information cycles of the hybrid media system, Couldry's (2012) treatment of how digital media are unique in the intensity with which they are implicated in everyday social practice, Bennett and Iyengar's (2008) call for a post-mass communication paradigm for understanding media effects, Shah et al's (2005) finding that there is a link between individuals' traditional media consumption patterns and their propensity to become politically engaged online, and, finally, Edgerly et al's (2016) recent work on how individuals 
appropriate existing media resources when they craft acts of political expression on Facebook.

News producers, political elites, and citizens participate in webs of complex interdependence that problematize what were once clearly differentiated roles in the production and distribution of news (Chadwick, 2017a). While professional journalists maintain their primacy as the originators and selectors of news, citizens who share content online contribute to the visibility of news - whether true, false, or exaggerated (Singer, 2014). In this environment, professionally-produced news not only reaches its audiences directly but also indirectly, when social media users share articles.

To date, the research on online news sharing has been almost entirely concerned with identifying the "factors for success" that make it more likely that news will be shared in the first place (Kümpel et al, 2015). In other words, sharing has mostly been treated as an outcome that can be predicted by a range of factors, such as emotional content (Papacharissi and de Fatima Oliveira, 2012); the presence of specific news frames (Valenzuela et al. 2017); the intensity of ongoing political events (Boczkowski and Mitchelstein, 2011); the characteristics of audience comments and ratings (Li and Sakamoto, 2014); and the role of elite users with large numbers of followers (Bakshy et al, 2011). Some work exists on the relationships between Facebook's affordances and personal feelings of community and involvement (Oeldorf-Hirsch and Sundar, 2015) and there is a growing body of work on the factors that lead users to post comments on news articles, as opposed to share news (see for example Weber, 2013).

But most existing studies rely solely on publicly-available social media data and there is little research that seeks to understand people's motivations for, and experiences of, sharing news. To our knowledge, no previous research has focused explicitly on the links between people's motivations for sharing news, the types of news they share, and the quality 
of behavior that results. No previous research has used the unique blend of survey data and data from observed news sharing behaviors of the kind we use here to study misinformation and disinformation. And no previous empirical research has focused on how different news sources might have elective affinities with people's propensity to misinform and disinform others on social media.

\section{Misinformation and disinformation in comparative context: from fake news factories to} tabloid news

When the "fake news" scandal emerged during the 2016 US presidential campaign it was widely perceived as an alien threat to elite US journalistic norms of professionalism, accuracy, and objectivity (Carlson, 2017). There is no doubt that fake news is a significant problem but how well do US understandings of it travel to other countries? The "purest" forms of fake news - outright fabrications created by online news "factories" that exploit advertising syndication systems for financial gain — have so far been rare or nonexistent in many countries. And in any case purely fabricated news is just one part of a spectrum of behaviors and artifacts problematic for the maintenance of liberal democratic norms. For alongside fake news there is the everyday online production and circulation of information that is exaggerated, sensationalized, selective, or assembled from a web of partial truths in hybrid networks of reputable and less reputable sources (Chadwick, 2017a: 271-284; Rojecki and Meraz, 2014).

If, as we argue, media are resources that people use to try to influence others on social media, in the UK the inconvenient truth is that key among the media that matter are articles published by large-circulation, mainstream tabloid outlets, whose daily stock-in-trade has always been news of dubious civic value. Tabloids have played significant roles in shaping British political life and there are few signs they are giving up their longstanding political 
missions. In the run-up to the UK's Brexit referendum in 2016, the right-wing tabloids the Sun, the Daily Mail, and the Daily Express strongly advocated for Britain's exit from the European Union (Deacon et al, 2016) and their online work was an important part of their strategy. Analysis of the hundred most-shared news stories on social media about UK politics in 2016 revealed no evidence of fake news factories but a great deal of problematic content in tabloid newspapers (Waterson, 2017). The most glaring example was a piece of only 377 words published by the Daily Express during the Brexit referendum campaign. Entitled "Major leak from Brussels reveals NHS will be KILLED OFF if Britain remains in the EU," the article claimed that trade deals between the EU and the United States would result in the EU seeking to "end all forms of state intervention in competition with the private sector," including, supposedly, the UK's publicly funded and highly popular National Health Service. This was pure misrepresentation, and the European Commission publicly refuted it. And yet, this Express story became the single most-shared news article on social media during the Brexit referendum campaign, with 464,000 shares, comments, and interactions on Facebook (Waterson, 2017).

Debate about the power exercised by the right-wing titles that dominate the UK press has been a perennial feature of general elections, popular commentary, and media scholarship since the 1970s (see for example Esser, 1999; McLachlan and Golding, 2000). In recent years, as print circulations have declined and new online news organizations such as Buzzfeed and the Huffington Post have reached mass audiences in the UK, it might seem that the era of tabloid dominance is drawing to a close. But the evidence suggests otherwise. As Table 1 shows, tabloids now attract huge audiences to their websites and mobile news applications. 
Table 1. Most-read UK newspaper titles in 2016

\begin{tabular}{|c|c|c|c|c|c|}
\hline Title & $\begin{array}{l}\text { Net print, } \\
\text { PC, and } \\
\text { mobile total } \\
\text { monthly } \\
\text { readership, } \\
\text { de- } \\
\text { duplicated } \\
\text { (millions) }\end{array}$ & $\begin{array}{l}\text { Average } \\
\text { print } \\
\text { monthly } \\
\text { readership } \\
\text { (millions) }\end{array}$ & $\begin{array}{c}\text { Average PC } \\
\text { readership, } \\
\text { November } \\
2016 \text { (millions) }\end{array}$ & $\begin{array}{c}\text { Total mobile } \\
\text { readership, } \\
\text { November } \\
\mathbf{2 0 1 6} \\
\text { (millions) }\end{array}$ & Type \\
\hline $\begin{array}{l}\text { Daily Mail \& } \\
\text { dailymail.co.uk }\end{array}$ & 29.1 & 9.9 & 8.0 & 19.9 & Tabloid \\
\hline The Sun \& thesun.co.uk & 26.2 & 10.1 & 2.8 & 19.0 & Tabloid \\
\hline $\begin{array}{l}\text { Daily Mirror \& } \\
\text { mirror.co.uk }\end{array}$ & 25.8 & 5.7 & 4.9 & 20.0 & Tabloid \\
\hline $\begin{array}{l}\text { The Guardian \& } \\
\text { theguardian.com }\end{array}$ & 22.7 & 4.1 & 7.7 & 17.2 & Quality \\
\hline $\begin{array}{l}\text { The Daily Telegraph \& } \\
\text { telegraph.co.uk }\end{array}$ & 21.4 & 3.8 & 7.3 & 15.2 & Quality \\
\hline Independent.co.uk & 16.9 & 0 & 4.4 & 14.4 & Quality \\
\hline $\begin{array}{l}\text { London Evening } \\
\text { Standard \& } \\
\text { standard.co.uk }\end{array}$ & 11.3 & 5.2 & 1.9 & 7.0 & Tabloid \\
\hline $\begin{array}{l}\text { Daily Express \& } \\
\text { express.co.uk }\end{array}$ & 10.6 & 2.7 & 3.0 & 6.1 & Tabloid \\
\hline $\begin{array}{l}\text { Daily Star \& } \\
\text { dailystar.co.uk }\end{array}$ & 6.2 & 2.4 & 1.0 & 3.3 & Tabloid \\
\hline $\begin{array}{l}\text { The Times \& } \\
\text { thetimes.co.uk }\end{array}$ & 5.8 & 4.2 & 0.8 & 1.6 & Quality \\
\hline
\end{tabular}

Source: Ponsford, 2017/UK National Readership Survey

Recent data also reveal tabloid news brands are thriving online, with the Mail, the Sun, and the Mirror all featuring in the top five online news sites by digital audience reach (OFCOM, 2017). As Figure 1 shows, the Mail and the Sun now reach about two thirds of the UK's total digital audience in any given month. 
Figure 1. Top 5 UK online news entities in April 2017, by millions of monthly users and percentage of total UK digital audience reached

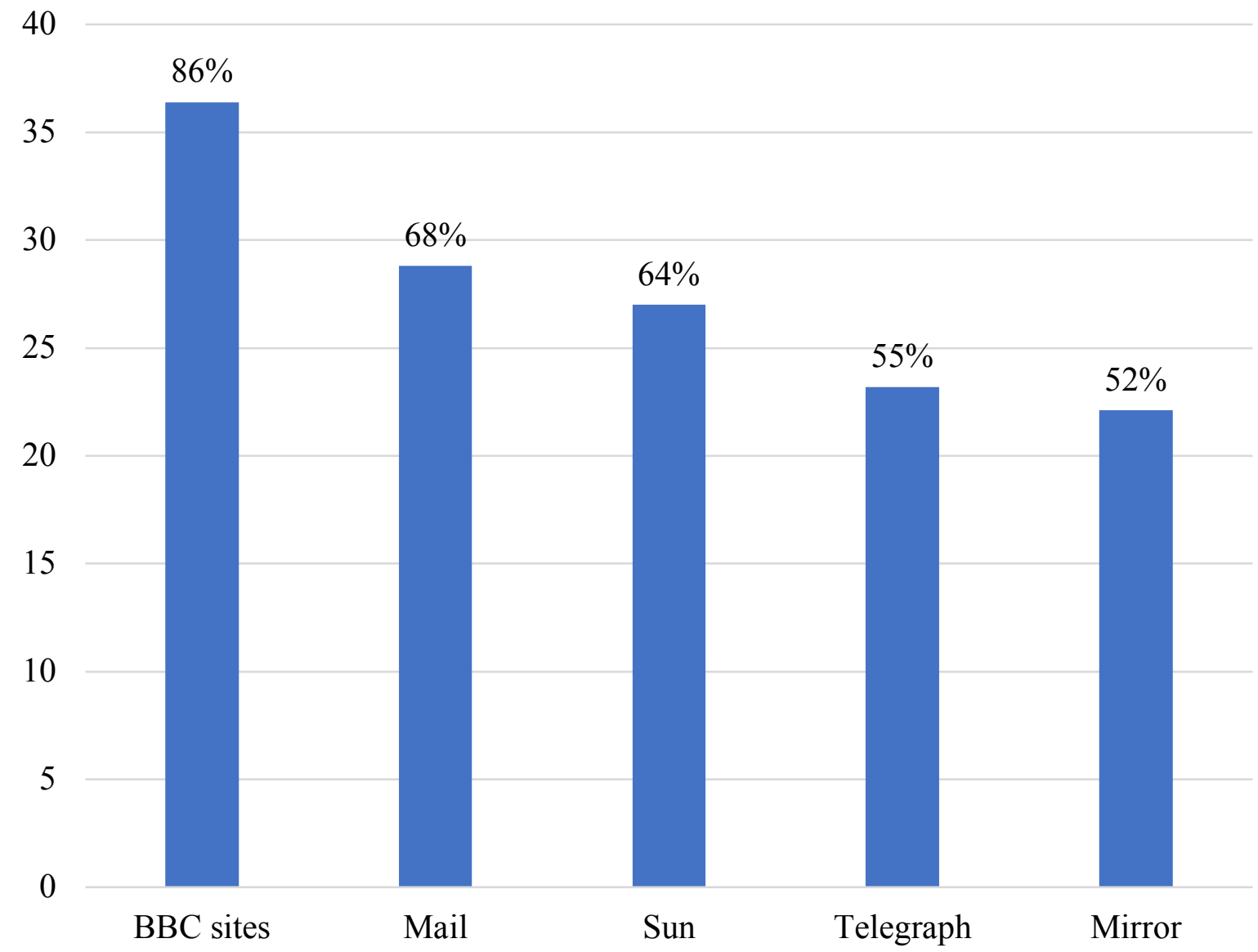

Note: People 18 years and over, April 2017. Source: OFCOM, 2017.

Of course, online there is plenty of ideologically-slanted news that does not originate with tabloids. A new generation of UK independent news websites such as Breitbart UK on the right and the Canary on the left contribute to this. As we later discuss, as part of our research for this article we also discovered that the Russian state broadcaster $R T$ features prominently in political news sharing networks on UK Twitter. Yet, important as these developments are, we argue that any study of the civic effects of news in the UK should begin from a media-systemic context in which tabloids are successfully adapting to technologically-driven shifts in the consumption, production, and circulation of news. 


\section{Research questions and hypothesis}

To disentangle how tabloid news sharing might shape the quality of online civic culture, we focus on three key explanations: users' motivations for sharing news on social media, the kinds of online networks in which users are embedded, and the types of media content they share. We explore whether these variables, together with a set of relevant controls, predict two behavioral outcomes: (1) sharing news on social media, either knowingly or unknowingly, that was either exaggerated or made up, and (2) being told by others on social media that the news one shared was not fully accurate, was exaggerated, or was made up.

We begin by asking RQ1: What motivations for sharing news on social media predict users' democratically-dysfunctional news sharing? and RQ2: What motivations for sharing news on social media predict being challenged by others for having engaged in democratically-dysfunctional news sharing?

News sharing on social media must also be considered in light of the relational context in which it occurs. When deciding whether to publish political messages, people consider whether members of their networks agree or disagree with their opinions (Vraga et al, 2015). Users may feel benevolent toward like-minded others and less inclined to deceive them, but they may also be less careful with what they share because they do not expect to be challenged. Conversely, people in more conflictual networks may be more willing to exaggerate and deceive to correct what they perceive as a hostile environment (Rojas, 2010), but the feeling of being in a minority may also constrain their expression (Askay, 2015) and caution them against sharing news whose veracity may be questioned. At the same time, accusing others of spreading exaggeration and falsehoods tends to generate conflict, and users who generally engage with conflictual networks may become used to dissonant interactions and not worry about avoiding confrontation (Vraga et al, 2015). 
In light of this range of potential expectations, we ask RQ3: What relationship is there between levels of agreement and disagreement in users' online networks and their engagement in democratically-dysfunctional news sharing? and RQ4: What relationship is there between levels of agreement and disagreement in users' online networks and their being challenged for having engaged in democratically-dysfunctional news sharing?

Next, using our media-as-resources perspective, we assess how different types of media sources might have elective affinities with problematic news sharing. Given our theory about the role of tabloids we reason that the more that users share tabloid news sources, the more likely they are to misinform and disinform others. Some news sharers on social media may be relatively careless about the truth of the information they share, while others may maliciously intend to deceive others. For both sets of users, tabloid news provides a fertile context of widely available, factually loose, exaggerated or false news. By the same token, we reason that sharing tabloid news is also likely to increase the probability of being challenged by other users. And an important issue in the debate about the problematic quality of online expression is whether the interpersonal networks of social media offer useful opportunities for correcting false or misleading information (Bode and Vraga, 2015; Margolin et al, 2017). Thus we formally hypothesize that (H1) the more that users share tabloid news on social media, the more likely they are to engage in democraticallydysfunctional news sharing (H1a) and be challenged by users in their social media networks for doing so (H1b).

\section{Research strategy, data, and design}

We adopted a novel, hybrid methods approach that used Twitter as a field site. By 2016, 25 percent of the British population used Twitter, making it second only to Facebook in usage for news (Reuters Institute for the Study of Journalism, 2017). To summarize, we integrated 
the analysis of large-scale, individual-level social media data ( $N=1,525,748$ tweets), website data $(N=17,989$ web domains), and news article data $(N=641$ articles $)$ with our own, customdesigned survey of Twitter users ( $N=1,313$ respondents). Our Online Appendix contains additional detail on our methods. ${ }^{1}$

We wanted to study users who had shared a range of types of news including tabloid news. Thus our first chosen population was Twitter users who, during the 2017 UK general election campaign, shared at least one news article related to politics published in one of the five most-read UK national tabloids: the Daily Mail, the Sun, the Daily Mirror, the Daily Express, and the Daily Star. We monitored these newspapers' websites for a week during the campaign (May 15-22, 2017) and recorded every article they published about UK politics. This resulted in a dataset of 641 news articles. To identify all the tweets that contained links to these articles we extracted the articles' hyperlinks and queried Twitter's Search API for tweets containing the links. In all, we found 83,881 tweets (including retweets) that linked to one of those articles. These tweets were posted by 28,552 unique users, a population we filtered to exclude likely bots, highly automated, and organizational accounts. ${ }^{2}$ Filtering yielded a population of 19,248 unique Twitter users.

We augmented this initial population of tabloid news sharers with a population of Twitter users who followed at least one of the five tabloids but who had not tweeted a link to any tabloid articles. This enabled us to include data for both actual and potential tabloid news sharers. After filtering these follower lists to exclude likely bots, highly automated, and organizational accounts we had a second sample of 20,391 users.

We then used an automated method to send survey invitations via personalized Twitter@messages to all users in both samples $(19,248+20,391)$. Users were invited to take our survey from June 5 to June 8, 2017 and we kept it open until June 11, three days after election day. Fully 1,422 users completed our survey - a participation rate of $3.6 \%$, in line 
with previous research based on similar methods (Vaccari, Chadwick and O'Loughlin, 2015; Chadwick, O'Loughlin and Vaccari, 2017). We only included in our analysis the 1,313 respondents who correctly answered an attention verification question. Of these, 1,066 had tweeted at least one tabloid article and 247 followed a tabloid account but had not tweeted any articles. Table A1 in our Online Appendix shows descriptive statistics for our sample and a comparison with a benchmark survey of a sample representative of the UK voting age population. The results of the benchmark survey show that our survey respondents were similar to those among the general UK online public who post political content on social media.

Outcome variables: misinformation, disinformation, and correction

Following the Pew Research Center's 2016 report on attitudes to fake news (Barthel, Mitchell and Holcomb, 2016) our survey asked: "Sometimes people might share news on social media that turns out not to be fully accurate or is exaggerated. In the past month, do you recall sharing a news story that..." Individuals could choose up to four among the following responses: "Seemed accurate at the time, but you later found was made up" (scored 1); "Was exaggerated, and you were not aware of this" (scored 2); "Was exaggerated, and you were aware of this" (scored 3); "You thought was made up when you shared it" (scored 4). Respondents who did not choose any of the above responses were scored as 0 . We rankordered the different behaviors to build a scale ranging from no reported dysfunctional news sharing (0), through misinformation to the most egregious offense of disinformation (4). This allowed us to place respondents on a five-point scale of dysfunctionality. (Respondents who selected more than one option were placed at the level in the scale corresponding to the most dysfunctional behavior they reported.) We reasoned that when a person shares news that seemed accurate at the time but which they subsequently found was made up, this is the 
lesser problem: it does not imply intentionality in the original moment and indicates a person at least bothers to make themselves aware that a story was misleading. At the other end of the scale lies the most problematic behavior — sharing news that a person thought was made up when they shared it. This reveals a willfully cavalier attitude to the truth.

Our second measure assesses the reactions people receive when they share misinformation and disinformation. We asked: "In the past month, do you recall being told by anyone on social media that the news you shared on social media was not fully accurate or exaggerated?" Respondents could choose one among four answers, and we built a four-point scale with the responses: "No, I do not recall that" (scored 0); "Yes, I was told the news I had shared was not fully accurate" (scored 1); "Yes, I was told the news I had shared was exaggerated" (scored 2), and "Yes, I was told the news I had shared was completely made up" (scored 3). As with our first outcome variable, we reasoned that if a person is told by others that the news they shared was "not fully accurate," this entails a less direct challenge than being told it was exaggerated. Highest on the scale is when a person is told by others that the news they shared was "completely made up." As we shall see, this response was chosen by a surprisingly large number of respondents.

\section{Explanatory variables I: motivations for sharing news on social media-} persuading/informing, debating, and entertaining/trolling

To understand people's motivations when they share political news, our survey asked: "When you share news about British politics on social media, how important are these different goals to you? To inform others, influence others, entertain others, upset others, please others, provoke discussions, or find out other people's opinions." Respondents were asked to evaluate each goal on a four-point scale from "not at all important" (0) to "very important" (3); we also included a “don’t know” option. 
To see how these seven motivations clustered we performed a principal component analysis on the responses. The results revealed three clear motivational clusters (see Table 2).

Table 2. Principal component analysis of motivations for sharing news on social media

\begin{tabular}{lccc}
\hline Motivation & \multicolumn{3}{c}{ Components } \\
\cline { 2 - 4 } & $\begin{array}{c}\text { Entertaining/ } \\
\text { Trolling }\end{array}$ & Debating & $\begin{array}{c}\text { Persuading/ } \\
\text { Informing }\end{array}$ \\
\hline To inform others & & & 0.714 \\
To influence others & & 0.666 \\
To find out other people's opinions & & 0.7286 & \\
To provoke discussions & 0.5807 & 0.6546 & \\
To entertain others & 0.5841 & & \\
To please others & 0.5169 & & \\
To upset others & & & \\
& 2.13682 & 1.24056 & 0.6297 \\
Eigenvalues & 0.3053 & 0.4825 & \\
Cumulative variance explained & & & \\
\hline
\end{tabular}

Note: With Varimax Rotation. Coefficients lower than 0.40 are not shown. $N=1,124$

We term these three motivations persuading/informing, debating, and entertaining/trolling. The first two labels are relatively straightforward but our use of the term entertaining/trolling for the clustered motivations to entertain, please, and upset others is perhaps less so. Trolling is a contested and context-dependent term that captures multiple practices, some of which are positive for preserving norms such as freedom of expression, open debate, and social experimentation. Nevertheless, if we think about a continuum of positive to negative online political behavior, we suggest trolling is comparatively negative, and it is all the more important to be clear about this in a so-called "post-truth" context. Phillips' (2015) detailed study showed that trolls maintain their identity by seeking to entertain themselves and others. They crave social approval and seek to impress with the visible traces of their disruption. Given that the motivations to entertain and please clustered 
strongly with the motivation to upset we believe the label entertaining/trolling captures an important and relatively democratically-dysfunctional motivation for news sharing. ${ }^{3}$

\section{Explanatory variables II: levels of disagreement in a user's online networks}

To assess whether our respondents tend to discuss politics on social media with likeminded or non-likeminded others, we asked: "Let us think about the people with whom you normally discuss British politics on social media. How many of them would you say you normally agree or disagree with?" Respondents could choose among five categories, ranging from complete agreement to complete disagreement. Those who expressed full or partial agreement were coded as 1; those who claimed to encounter balanced views were coded as 0 ; and those who reported disagreement with most or all of their networks were coded as -1 . We excluded respondents who answered "I do not discuss British politics on social media" and "Don't know."

Explanatory variables III: digital trace data for types of news shared by our survey respondents

Surveying Twitter users meant we were able to collect the tweets our respondents had posted and identify the news types they actually shared on Twitter. The day after the election, we queried the Twitter Search API to collect the maximum possible number of publicly available tweets for each respondent - the last 3,200 per person. Because we treated news types shared as an explanatory variable we restricted our analysis to tweets posted from the beginning of the election campaign up until the day before we fielded our survey (April 18-June 4). This yielded $1,525,748$ tweets posted by 1,289 survey respondents. ${ }^{4}$ Of these 1.53 million tweets, 776,880 contained one or more hyperlinks. We extracted the web domain names from these hyperlinks and established that respondents had shared links from 17,989 unique web 
domains. But the list of shared domains had a classic long-tail distribution: just 329 domains accounted for 90 percent of all the domains our users shared. We therefore decided to rank order the domains according to the number of tweets that linked to them and the number of our survey respondents who had shared them.

We then excluded domains that were not news sites and classified the 50 top-ranked domains in our index by news type. We distinguished between broadcasters, quality newspapers, tabloid newspapers, international news, online-native news, and state broadcasters. Together, these top 50 domains accounted for 127,600 URLs shared in tweets by our respondents. Due to the skewed distribution of the shared news variables, we took the $\log$ of the numbers of tweets, after adding 1 so that users who had shared no tweets from any category would still be included in our analyses. The calculated rankings and the full list of the top 50 news sources, together with their classifications, can be found in Table A2 in our Online Appendix. ${ }^{5}$ Our respondents clearly shared from a wide variety of news outlets, most of which were not tabloids. Although we do not claim that our sample is fully representative of Twitter users, equally, it goes well beyond those who only read and share tabloid news online.

\section{Control variables: socio-demographics and political attitudes}

Finally, we integrated the two most important sources of data we had gathered about our sample of Twitter users - their survey responses and the number of tweets they had shared linking to each of the six news types - and entered these into ordered logistic regression models. We imputed missing data to ensure our analyses did not suffer from biases due to listwise deletion. ${ }^{6}$

Our models controlled for a range of variables. Given the particular demographics of tabloid readers and Twitter users, we controlled for gender, age, income, and education. As 
our sample included users who shared political news, we controlled for political attitudes such as interest in politics, political efficacy, and satisfaction with democracy. Since each tabloid has specific partisan leanings and because strong partisans are more willing to believe false information confirming their preferences (Flynn, Nyhan and Reifler, 2017: 131-137), we control for users' ideology and ideological extremism (measured as ideology squared).

\section{Findings and Discussion}

We first present some descriptive statistics on dysfunctional news sharing behavior. As Table 3 shows, a surprisingly large number of our respondents admitted to democraticallydysfunctional news sharing.

Table 3. Misinformation and disinformation as democratically-dysfunctional news sharing behaviors

\begin{tabular}{lll}
\hline Shared news on social media in the past month that* & Frequency & Percent \\
\hline 0. No response selected & 391 & 32.3 \\
1. Seemed accurate at the time, but you later found was made up & 362 & 29.9 \\
2. Was exaggerated, and you were not aware of this & 379 & 31.3 \\
3. Was exaggerated, and you were aware of this & 207 & 17.1 \\
4. You thought was made up when you shared it & 108 & 8.9 \\
Total & 1,210 \\
\hline \multicolumn{3}{l}{} \\
\hline Was in the past month told by anyone on social media that & Frequency & Percent \\
\hline 0. I do not recall being told any of these & 779 & 64.9 \\
1. The news I had shared was not fully accurate & 221 & 18.4 \\
2. The news I had shared was exaggerated & 107 & 8.9 \\
3. The news I had shared was completely made up & 94 & 7.8 \\
Total & 1,201 & 100 \\
\hline
\end{tabular}

* Percentages do not add up to 100 because more than one response could be selected.

Fully two-thirds (67.7 percent) admitted to having shared news that was problematic in some way in the past month. In particular, 8.9 percent admitted to having willfully shared news that was made up and 17.1 percent willfully shared news that was exaggerated. More 
than a third (35.1 percent) also reported being challenged for sharing news that was not fully accurate, was exaggerated, or was made up. The extent of these behaviors is disturbing. The limitations of our sample notwithstanding, these results reveal that democraticallydysfunctional news sharing behavior is common practice for significant numbers of UK Twitter users who share political news on social media. But, turning to our regression analysis, what are the factors that explain these outcomes?

As the left panel of Table 4 shows, tabloid news media play a significant role in enabling democratically-dysfunctional news sharing behavior. The number of tabloid news articles shared on Twitter is a positive and significant predictor of the likelihood of reporting sharing news on social media that was either exaggerated or fabricated. This finding supports the first part of our hypothesis (H1a) that the more users share tabloid news on social media, the more likely they are to engage in democratically-dysfunctional news sharing. There were no significant associations between dysfunctional behavior and sharing news from any other news types. As we theorized, there are elective affinities between mainstream UK tabloid sources and news sharing that results in misinformation and disinformation.

The relationship between tabloids and dysfunctional news sharing becomes clearer still if we consider a hypothetical respondent whose characteristics are equal to the mean values in the variables included in Table 4 (apart from the number of tabloid news articles shared). If a statistically-average respondent shared just one tabloid news story in the entire 47-day period for which we analyzed tweets, our model estimates that there is a 62 percent probability that this respondent would have reported dysfunctional news sharing behavior of some kind. The probabilities of this average respondent committing the most serious offenses in our scale — knowingly sharing news that is exaggerated or false-are estimated at 10 percent and 6 percent, respectively. If an average respondent shared one tabloid news story 
Table 4. Explaining democratically dysfunctional-news sharing behaviors

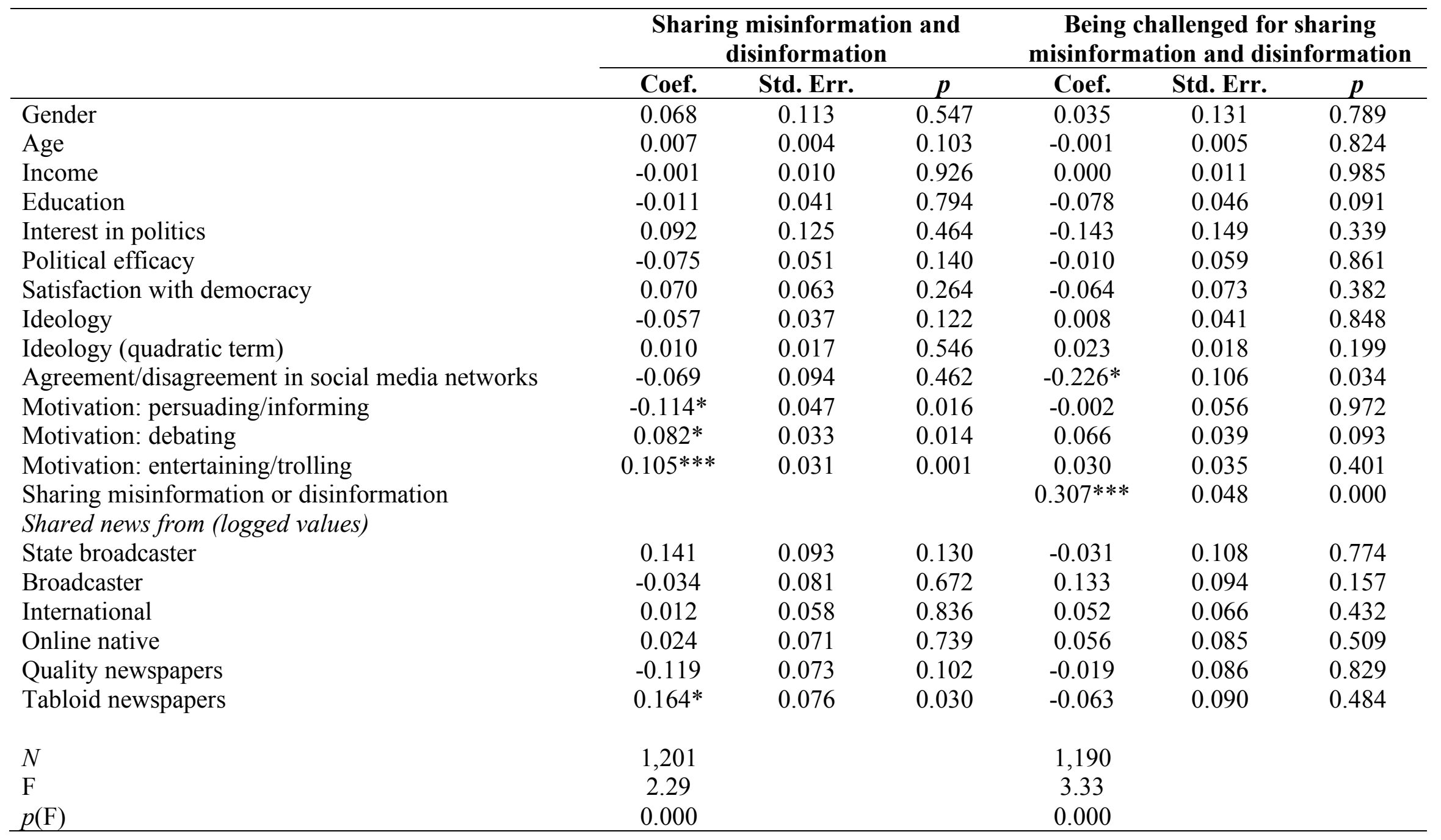

Note: $* * * \mathrm{p} \leq .001 * * \mathrm{p} \leq .01 * \mathrm{p} \leq .05$. We do not report the conventional goodness of fit statistic (Log-likelihood) because it cannot be computed for analyses based on multiply imputed data. 
per day (i.e. 47 stories in total), our model estimates there is a 72 percent probability that they would report dysfunctional news sharing, while, again, the two most severe offensesknowingly sharing news that is exaggerated or false - are estimated at 15 percent and 10 percent respectively. ${ }^{7}$ If we consider the massive scale of social media networks, it is clear from our findings that, on social media, there is a great deal of democratically-dysfunctional news sharing in relation to UK politics and tabloid articles are an essential ingredient in it.

In contrast, we found no evidence that sharing news from online-native news sites predicted dysfunctionality. In the fallout from the 2017 UK general election there was much discussion about the growth of sensationalism in online political news as a result of the popularity of new, ideologically-slanted news sites such as, for example, Breitbart $U K$ and Westmonster on the right and the Canary and Evolvepolitics on the left. There is also an ongoing debate about the contributions to civic life of the so-called "clickbait" general interest online-native sites such as Buzzfeed and the Huffington Post (Scacco and Muddiman, 2016). Equal concern has been expressed about whether the Russian state broadcaster $R T$ acts as a propaganda arm of the Kremlin, distributing news aimed at destabilizing the West. Online-native news sites featured prominently in the top 50 most-shared news sources among our respondents, as did $R T$, which confirms that the latter has become a widely-shared political source on Twitter in the UK. It is striking, however, that among our respondents, sharing online-native sources and sharing $R T$ (the only state broadcaster in our top 50 sources) had no statistically-significant relationships with misinformation and disinformation behaviors. Only mainstream UK tabloid newspapers attained that dubious status.

Table 4 shows that all clusters of motivations for sharing news predict dysfunctional behavior and with statistically significant coefficients, providing an answer to our first research question. But while entertaining/trolling and debating are positively associated with dysfunctionality, persuading/informing is negatively associated with it. In other words, those 
who are motivated to entertain/troll and debate with others are more likely to engage in misinformation and disinformation when they share news. Those who seek to persuade/inform others are less likely to do so.

That the motivation to entertain/troll predicts misinformation and disinformation behaviors is unsurprising. In essence, these are people's motivations being fulfilled by their behavioral rewards. Still, it is the relatively weak civic character of this behavior that we argue ought to be of concern. The goals that comprise this motivational cluster-to entertain, please, or upset others - are all focused on eliciting emotional responses. For these users, news sharing is not about seeking to inform others; the quality of the news they share appears to be unimportant. Indeed, perhaps the more sensational, ludicrous, or exaggerated the news is, the better it fits with the motivation to disrupt the rationality and veracity upon which political discussion must, in the final reckoning, depend. Of course, the motivation to entertain others may be civic in orientation. There is now a body of research on the role of political comedy in promoting engagement (for a good overview see Delli Carpini, 2012). However, this work has overwhelmingly focused on broadcast television shows, whose satire fundamentally depends on a baseline of factuality and tightly-scripted and professionallyproduced texts - the broadcasts — from which audiences might learn about politics. Social media provide a much looser context, where the choice of media-as-resources is much greater and where there are far more diverse opportunities for sharing problematic news content, should a user be motivated to do so. In this context, we caution against interpreting the outcomes of the entertaining/trolling motivation as unalloyed civic goods.

That said, our results do reveal a positive and significant relationship between the motivation to debate with others and democratically-dysfunctional news sharing. Clearly, users with more civically-oriented motivations than entertaining/trolling still tend to mobilize news for misinformation and disinformation on social media. But if misinformation and 
disinformation are an essential part of the repertoire of those who seek to debate with others, we suggest this might reveal a "race to the bottom" in online discourse. Those motivated to debate may see sharing problematic news as a cultural norm; a practice that is simply part of "what it takes" to engage politically on social media in order to attract attention and nudge others to take positions. This raises the worrying possibility that there might be a social media logic of sharing exaggerated and fabricated news and that this logic shapes the behavior even of those who begin from relatively civic motivations.

Our findings also reveal that the levels of agreement and disagreement in users' social media networks do not predict whether a user will engage in dysfunctional news sharing. The coefficient for this variable is not significant in the left panel of Table 4. This answers our third research question. However, levels of network agreement and disagreement do play a role in correcting dysfunctional behavior when it occurs. The coefficient for networks is negative and significant in the right panel of Table 4, which indicates that users are more likely to be challenged for their democratically-dysfunctional behavior if they tend to discuss politics on social media with people with whom they disagree, answering our fourth research question. It is possible to imagine plenty of scenarios in which political disagreement between the ideologically-divided leads to factual disputes or accusations that a news article is exaggerated. Over time, this might make people think twice about the quality of the news they decide to share. However, the logical downside — and it is a big downside — is that the more people engage with users who are politically like-minded, the less likely it is that they will face challenges for dysfunctional behavior.

We find some further evidence of corrective behavior. To provide an initial test of the second part of our hypothesis (H1b) that the more dysfunctional news sharing behaviors users engage in, the more likely they are to be challenged, in Table 4 we included as an independent variable (see left panel) the scale of dysfunctional news sharing that was the 
dependent variable in the central panel. The coefficient for this variable is positive and significant, thus confirming our hypothesis. There appears on the surface to be a healthy and intuitive connection between dubious behavior and receiving reprimands.

At the same time, however, we must stress that large numbers of respondents who engaged in dysfunctional news sharing did not recall being challenged at all. Our model estimates that a statistically-average respondent who engaged in the most dysfunctional behavior of disinformation — knowingly sharing fabricated news — had only a 52 percent probability of being challenged in any way. And this is as good as it gets, because the probability of the statistically-average respondent being challenged for committing the less serious act of knowingly sharing news that was merely exaggerated is 43 percent. Misinformation, while still common, was also quite likely to go unchallenged. Those who said they shared news that was exaggerated but were not aware that it was at the time had a 39 percent probability of being challenged, while those who shared news that seemed accurate at the time but who later found it was completely made up had only a 23 percent probability of being challenged. Social media correction is an imperfect mechanism. Yes, the most egregious behaviors are more likely to be countered but there are plenty of acts of misinformation and disinformation that receive no reprimands.

Finally, and most troublingly, we find no statistically-significant relationships between users' motivations (persuading/informing, debating, and entertaining/trolling) and the probability of their being challenged by others for dysfunctional news sharing. This answers our second research question. Equally, there is no correlation between the news types respondents shared and the likelihood of being challenged by others (H1). This means that those with the strongest motivations to behave in democratically-dysfunctional ways on social media and those who shared more tabloid news, which we have shown plays a role in 
enabling dysfunctional behaviors, are not more likely to be challenged by people in their social media networks.

\section{Conclusion}

In the contemporary media environment, understanding how news affects citizens' knowledge, attitudes, and behaviors requires that we account for the multiple mechanisms by which content travels - directly, from news organizations to audiences, and indirectly, through sharing by ordinary users on digital media platforms. It also requires that we explain why different types of citizens share different types of news and how both social media affordances and media content enable citizens to achieve their goals. Tackling these questions requires innovative research designs that combine analysis of news media content, selfreports from relevant groups of social media users, and digital trace data, as we have done in this study.

We find that UK tabloid newspapers negatively affect the quality of civic life on social media because they provide a fertile context for misinformation and resources for disinformation. During the 2017 UK general election campaign two-thirds (67.7 percent) of our respondents admitted to sharing problematic news on social media, which shows that this phenomenon is widespread but also that people are at least prepared to acknowledge their responsibility when asked in a survey. But most significantly, the more that users shared tabloid news articles on Twitter, the more likely they were to share news that was exaggerated or made up. There was no relationship between such democraticallydysfunctional behavior and sharing news from other sources-quality newspapers, broadcasters, online-native news sites, international news, not even the Russian state broadcaster $R T$. 
Equally troubling is our finding that the more users engage with politically likeminded others online, the less likely it is that they will be challenged for dysfunctional behavior. Over the longer term, these people are less likely to encounter the kind of opposition that might make a difference to the quality of the news they share. At the systemic level, this raises the worrying prospect that the homophily that characterizes some, though by no means all (Barberá et al, 2015), political networks on social media may, in part, be animated by news sharing based on misinformation and disinformation. This might not be such a problem so long as homophilic networks remain small and politically marginal. But if this is the typical experience of large numbers of individuals on social media — and the size of tabloid reach online indicates that large numbers are involved — norms of correction are unlikely to become widely embedded. Over time, this may lead to low levels of awareness of the quality of different news types, a damaging cultural expectation that "anything goes" when sharing news online, and the impossibility of establishing a common ground of facts that enable citizens to engage in meaningful discussion across political divides. In short, animated by tabloid news, politics on social media may become a shouting match —of the deaf.

While it is heartening that more seriously dysfunctional behavior - the intentional sharing of news that is exaggerated or fabricated - is more likely to be challenged by other social media users, there is, nevertheless, a startlingly high probability that dysfunctional sharing will go unchallenged. And users motivated to entertain/troll are not more likely to be reprimanded for their behavior. Social media remains an imperfect mechanism for correcting behavior that undermines civic culture online. Our findings suggest that the tragedy of the social media commons is that the correction of misinformation and disinformation is more likely to fail in precisely those circumstances when correction is most needed. 
Our study has broader implications for the functioning of democracy. At the systemic level, tabloid newspaper logics are now integrating with social media logics and enabling people to spread misinformation and disinformation. This leads to dysfunctional sharing behaviors even among more civic-minded social media users. According to our media-asresources perspective, the raw materials for misinformation and disinformation must come from somewhere, and news is always likely to be central to this process. But when the quality of those external sources is relatively poor, and the sharing of those sources is linked to behavior that erodes civic culture online, we should be concerned. Future research could shed further light on the manifold aspects of what we see as the indirect, distributed tabloidization of the UK's and other countries' social media environments.

A final point concerns the need to broaden the range of factors we consider in the ongoing debate about misinformation and disinformation. In the US context, the fake news crisis of 2016 was rightly met with calls for a restatement of the values of professional journalism. As our study shows, however, in some countries the content produced by some professional media outlets might be significant in the diffusion of misinformation and disinformation. Debates about fake news ought to pay attention to how hybrids of older and newer media—in this case social media combined with digitally-adaptive tabloid media—can explain democratically-dysfunctional online behavior. Thus, the role of elite and nonelite media, the specific features of national media systems, and the motivations and behaviors of ordinary social media users should all feature in future debates about the democratic quality of news.

\section{Acknowledgements}


Our thanks go to Amy P. Smith for her steadfast research assistance. Pablo Barberá and Patricia Rossini provided invaluable help with data wrangling. Eszter Hargittai gave useful advice on survey design. Any errors or shortcomings are our own.

\section{Funding}

The authors received financial support from the Centre for Research in Communication and Culture at Loughborough University and the New Political Communication Unit at Royal Holloway, University of London for the research and authorship of this article.

\section{References}

Askay, D. A. (2015). Silence in the crowd: The spiral of silence contributing to the positive bias of opinions in an online review system. New Media \& Society, 17(11), 18111829.

Bakshy, E, Mason, W A, Hofman, J M, and Watts, D J (2011) Everyone's an influencer: quantifying influence on Twitter. WSDM '11: Proceedings of the Fourth ACM International Conference on Web Search and Data Mining.

Barberá, P, Jost, J T, Nagler, J, Tucker, J A, and Bonneau R (2015) Tweeting from left to right: Is online political communication more than an echo chamber? Psychological science, 26(10), 1531-1542.

Barthel, M, Mitchell, A and Holcomb, J (2016) Many Americans Believe Fake News is Sowing Confusion. Washington, DC: Pew Research Center. Available at: http://assets.pewresearch.org/wpcontent/uploads/sites/13/2016/12/14154753/PJ_2016.12.15_fake-news_FINAL.pdf

Bennett, W L and Iyengar, S (2008). A new era of minimal effects? the changing foundations of political communication. Journal of Communication 58(4): 707-731. 
Bird, S E (1998) News we can use: an audience perspective on the tabloidization of news in the United States. Javnost-The Public 5(3): 33-49.

Boczkowski, P J and Mitchelstein, E (2011) How users take advantage of different forms of interactivity on online news sites: clicking, e-mailing, and commenting. Human Communication Research 38(1): 1-22.

Bode, L and Vraga, E K (2015) In related news, that was wrong: the correction of misinformation through related stories functionality in social media. Journal of Communication 65(4): 619-638.

Carlson, M (2017) Facebook in the news: Social media, journalism, and public responsibility following the 2016 Trending Topics controversy. Digital Journalism, 1-17, doi: $10.1080 / 21670811.2017 .1298044$

Chadwick, A (2017) The Hybrid Media System: Politics and Power $2^{\text {nd }}$ Edition, New York: Oxford University Press.

Chadwick, A, O’Loughlin, B, \& Vaccari, C (2017) Why People Dual Screen Political Debates and Why It Matters for Democratic Engagement. Journal of Broadcasting and Electronic Media 61(2): 220-239.

Couldry, N (2012) Media, Society, World: Social Theory and Digital Media Practice. Cambridge: Polity.

Deacon, D, Wring, D, Harmer, E, Stanyer, J and Downey, J (2016) Hard evidence: analysis shows extent of press bias towards Brexit. Conversation, June 16, 2016. Available at: https://theconversation.com/hard-evidence-analysis-shows-extent-of-press-bias-towardsbrexit-61106

Delli Carpini, M X (2012) Entertainment media and the political engagement of citizens. In: Semetko H A and Scammell M (eds.) Sage Handbook of Political Communication. London: Sage, pp. 9-21. 
Dewey, J. (1927) The Public and its Problems London: George Allen \& Unwin.

Edgerly, S, Thorson, K, Bighash, L, and Hannah, M (2016) Posting about politics: media as resources for political expression on Facebook. Journal of Information Technology \& Politics 13(2): 108-125.

Esser, F (1999) “Tabloidization” of news: a comparative analysis of Anglo-American and German press journalism. European Journal of Communication 14(3): 291-324.

Flynn, D J, Nyhan, B, and Reifler, J (2017) The nature and origins of misperceptions: Understanding false and unsupported beliefs about politics. Advances in Political Psychology, 38(S1), 127-150.

Habermas, J (1996) Between Facts and Norms: Contributions to a Discourse Theory of Law and Democracy, tr. William Rehg. Cambridge, MA: MIT Press.

Jack, C (2017) Lexicon of Lies: Terms for Problematic Information. New York: Data \& Society Research Institute.

Kümpel, A S, Karnowski, V and Keyling, T (2015) News sharing in social media: a review of current research on news sharing users, content, and networks. Social Media + Society 1(2): 1-14.

Li, H and Sakamoto, Y (2014) Social impacts in social media: An examination of perceived truthfulness and sharing of information. Computers in Human Behavior 41: 278287.

Lippman, W (1922) Public Opinion. New York: Harcourt, Brace \& Co.

Margolin, D B, Hannak, A and Weber, I (2017) Political fact-checking on Twitter: when do corrections have an effect? Political Communication, 1-24, doi: $10.1080 / 10584609.2017 .1334018$

McLachlan, S and Golding P (2000) Tabloidization in the British press: a quantitative investigation into changes within British newspapers from 1952-1997. In: Sparks C and 
Tulloch J (eds.) Tabloid tales: global debates over media standards. London: Hampton Press, pp. 75-90.

Oeldorf-Hirsch, A and Sundar, S (2015) Posting, commenting, and tagging: effects of sharing news stories on Facebook. Computers in Human Behavior 44: 240-249.

OFCOM (2017) News Consumption in the UK. June 29, 2017. Available at: https://www.ofcom.org.uk/_data/assets/pdf_file/0017/103625/news-consumption-uk2016.pdf

Papacharissi, Z and de Fatima Oliveira, M (2012) Affective news and networked publics: the rhythms of news storytelling on \#Egypt. Journal of Communication 62(2): 266282.

Phillips, W (2015) This Is Why We Can't Have Nice Things: Mapping the Relationship Between Online Trolling and Mainstream Culture. Cambridge, MA: MIT Press.

Ponsford, D (2016) Sun and Mail Online both take down stories claiming Jeremy Corbyn was 'dancing a jig' on way to Cenotaph. Press Gazette, November 24. Available at: http://www.pressgazette.co.uk/bbc-presenter-andrew-marr-has-defended-decision-tointerview-far-right-leader-marine-le-pen-on-remembrance-sunday

Reuters Institute for the Study of Journalism (2017) Reuters Digital News ReportUnited Kingdom. Available at: http://www.digitalnewsreport.org/survey/2017/unitedkingdom-2017

Rojas, H (2010) "Corrective" actions in the public sphere: How perceptions of media and media effects shape political behaviors. International Journal of Public Opinion Research, 22(3), 343-363.

Rojecki, A and Meraz, S (2014) Rumors and factitious informational blends: the role of the web in speculative politics. New Media \& Society 18(1): 25-43. 
Scacco, J M and Muddiman, A (2016) Investigating the influence of "clickbait" news headlines. Engaging News Project Report. Available at: https://mediaengagement.org/wpcontent/uploads/2016/08/ENP-Investigating-the-Influence-of-Clickbait-News-Headlines.pdf Schudson, M (1998) The Good Citizen: A History of American Civic Life. New York: Martin Kessler.

Shah, D V, Cho, J, Eveland, Jr., W P and Kwak, N (2005) Information and expression in a digital age: modeling internet effects on civic participation. Communication Research 32(5): 531-565.

Singer, J B (2014) User-generated visibility: Secondary gatekeeping in a shared media space. New Media \& Society 16(1): 55-73.

Vaccari, C, Chadwick, A, \& O’Loughlin, B (2015) Dual Screening the Political: Media Events, Social Media, and Citizen Engagement. Journal of Communication 65(6): $1041-1061$.

Valenzuela, S, Piña, M, \& Ramírez, J (2017) Behavioral effects of framing on social media users: How conflict, economic, human interest, and morality frames drive news sharing. Journal of Communication, 67(5), 803-826.

Vraga, E K, Thorson, K, Kligler-Vilenchik, N, \& Gee, E (2015) How individual sensitivities to disagreement shape youth political expression on Facebook. Computers in Human Behavior, 45, 281-289.

Waterson, J (2017) Britain has no fake news industry because our partisan newspapers already do that job. Buzzfeed UK. January 24, 2017. Available at: https://www.buzzfeed.com/jimwaterson/fake-news-sites-cant-compete-with-britains-partisannewspape?utm_term=.bcnKEzoDn\#.dxMP8ln4N 
Weber, P (2013) Discussions in the comments section: factors influencing participation and interactivity in online newspapers' reader comments. New Media \& Society 16(6): 941-957.

\section{Author biographies}

Andrew Chadwick is Professor of Political Communication in the Centre for Research in Communication and Culture and the Department of Social Sciences at Loughborough University.

Cristian Vaccari is Reader in Political Communication in the Centre for Research in Communication and Culture and the Department of Social Sciences at Loughborough University.

Ben O'Loughlin is Professor of International Relations in the Department of Politics and International Relations at Royal Holloway, University of London. 


\section{Notes}

${ }^{1}$ See the Online Appendix at: http://files.andrewchadwick.com/nms2018/onlineappendix.pdf

${ }^{2}$ See the Online Appendix at: http://files.andrewchadwick.com/nms2018/onlineappendix.pdf

${ }^{3}$ We thank anonymous reviewer \#1, whose comments on the first version of this paper helped us think through our terminology.

${ }^{4}$ In the period between our survey and our collection of their tweets 24 users either protected or closed their accounts or had their accounts suspended by Twitter.

${ }^{5}$ http://files.andrewchadwick.com/nms2018/onlineappendix.pdf

${ }^{6} \mathrm{http}: / /$ files.andrewchadwick.com/nms2018/onlineappendix.pdf

${ }^{7}$ Across our whole sample, the mean number of tabloid news articles shared was 27.4, with a standard deviation of 2.8. Twenty-one percent of our respondents shared one or no tabloid news stories in total, and 13 percent shared one or more tabloid news articles per day. 